\title{
Prenatal bowel dilatation: congenital chloride diarrhoea
}

A healthy primigravida had moderate polyhydramnion (amniotic fluid index (AFI) $=230 \mathrm{~mm}$ ) at 32 gestational weeks. The fetus had dilated, fluid filled, and frequently contracting small bowels filling the whole abdomen (figs 1 and 2), most likely representing distal small bowel atresia or stenosis. At 33 weeks, increasing polyhydramnion $(\mathrm{AFI}=430 \mathrm{~mm}$ ) led to the aspiration of $1180 \mathrm{ml}$ of clear amniotic fluid not stained with meconium. At 36 weeks, the patient had an uneventful spontaneous delivery of a female infant with a slightly distended abdomen. As plain abdominal and contrast colon radiographs were normal and the baby was stable, oral feeding was introduced. No passage of meconium was observed. There was no vomiting, but at the age of 2 days she had loose watery stools and had developed hyperbilirubinaemia. She did not gain weight during the following 12 days and became increasingly tired. Her abdomen was distended with visible intestinal contractions (fig 3).

She had metabolic alkalosis and abnormal laboratory variables: serum $\mathrm{Na}^{+}, 104 \mathrm{mmol} / \mathrm{l}$;

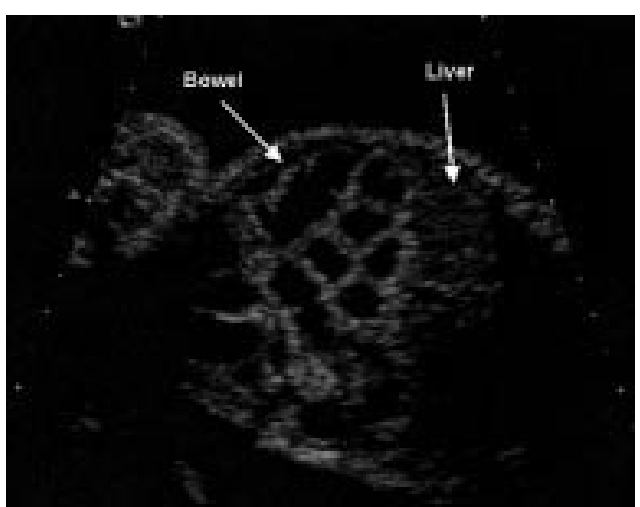

Figure 1 Ultrasonograph showing fluid filled small bowel filling the abdomen.

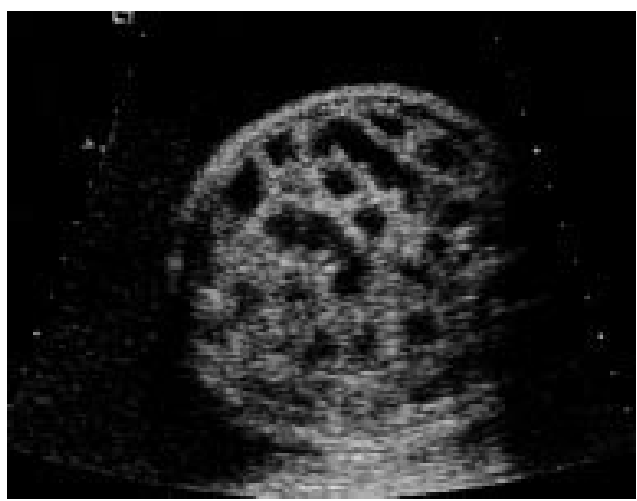

Figure 2 Ultrasonograph showing fluid filled small bowel.

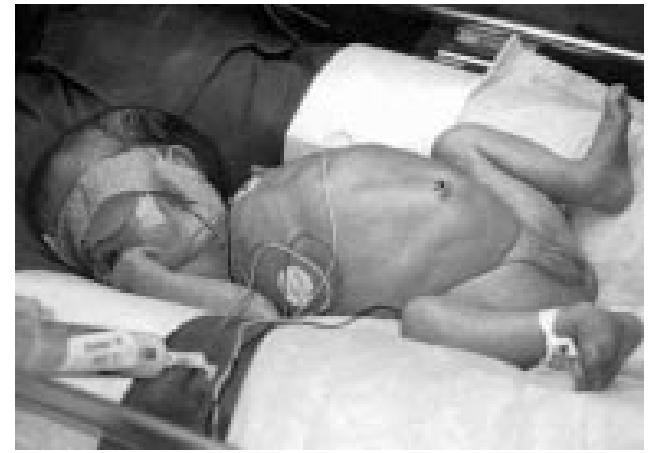

Figure 3 Female infant with distended abdomen and visible intestinal contractions.

serum $\mathrm{K}^{+}, 2.7 \mathrm{mmol} / 1$; serum $\mathrm{Cl}^{-}, 57 \mathrm{mmol} / 1$. Further investigation showed a faecal concentration of $\mathrm{Na}^{+}(25 \mathrm{mmol} / \mathrm{l}), \mathrm{K}^{+}(48 \mathrm{mmol} / \mathrm{l})$, and $\mathrm{Cl}^{-}$(46 mmol/1) changing to 103,33 , and $160 \mathrm{mmol} / 1$ respectively. Hypovolaemia and hyponatraemia led to increased renin production and hyperaldosteronism.

Normal radiographic findings, no vomiting, and the absence of meconium and normal stools led to the suspicion of congenital watery diarrhoea. The picture of preterm birth, polyhydramnion, no passage of meconium, abdominal distension, hyperbilirubinaemia, hyponatraemia, hypokalaemia, and hypochloraemic metabolic alkalosis made the diagnosis of congenital chloride diarrhoea highly probable, and this was confirmed by the high faecal chloride concentration. The high renin and aldosterone levels corresponded well to other documented observations. ${ }^{1}$

There is no treatment to cure the diarrhoea, but children with this condition become toilet trained at a normal age, their social adjustment is not impaired, and they usually live a perfectly normal life. ${ }^{2}$ Congenital chloride diarrhoea should be considered as a possible diagnosis in cases in which prenatal ultrasound examinations show distended bowels in combination with polyhydramnios.

S HUSU

N NELSON

Division of Pediatrics, Department of Health and

Environment, University Hospital, SE-581 85 Linköping, Sweden

nina.nelson@lio.se

A SELBING

Division of Obstetrics, Department of Health and

Environment, University Hospital, SE-581 85 Linköping, Sweden

1 Kagalwalla AF. Congenital chloride diarrhea. A study in Kagalwalla AF. Congenital chloride diarrhea. A
Arab children. F Clin Gastroenterol 1994;19:36-40. 2 Holmberg C, Perheentupa J, Launiala K, et al. Congenital Holmberg C, Perheentupa J, Launiala K, et al. Congen
chloride diarrhoea. Arch Dis Child 1977;52:255-67. 